\title{
Fabrication of Graphene-CuO Nanocomposite with Improved Photocatalytic Degradation for Palladium Solution under Solar Light Irradiation
}

\author{
B. Prashanti, T. Damodharam* \\ Department of Environmental Sciences, Sri Venkateswara University, Tirupati - 517 502, Andhra Pradesh, India.
}

\section{ART ICLE DETAILS}

\section{Article history:}

Received 06 August 2018

Accepted 23 August 2018

Available online 04 September 2018

\section{Keywords:}

GO-CuO Nanocomposites

Spectral Characterization

Photocatalytic Activity

\begin{abstract}
A B S T R A C T
A facile synthesis of graphene oxide-copper oxide nanocomposite (GO-CuO) was performed by using wet chemical method of graphene oxide and copper acetate precursors. The nanocomposite was characterized and intercalated with Raman spectroscopy, FE-SEM, TEM, SAED and EDAX. The crystalline nature was studied from P-XRD. Photocatalytic degradation of palladium ion was studied by using UVVIS spectrophotometer. Significant high-performance photocatalytic activity of GO-CuO nanocomposite was exhibited on palladium ions degradation under solar light.
\end{abstract}

\section{Introduction}

There is great interest in the removal and recovery of precious metals such as gold, palladium, platinum and other noble metals from wastewater. The two most important reasons and motivations for precious metal removal are the economic impact of losing these metals and their environmental concerns [1]. They are common contaminants in wastewater and many of them are known to be toxic or carcinogenic. Trace amounts of these precious metals can be found in some wastewaters as a result of mining [2], electroplating industries [3], or electronic and jewellery manufacturing. However, such wastewaters contain precious metals not recovered from precipitation methods with concentrations around $10 \mathrm{mg} / \mathrm{L}$, and other valuable metals with concentrations ranging from several $\mathrm{mg} / \mathrm{L}$ to more than $10,000 \mathrm{mg} / \mathrm{L}$. The most current, efficient and economical method to remove heavy metals by photocatalytic degradation using day-light driven in the presence of an appropriate photocatalyst that is able to promote the reduction of toxic metals to favorable by products.

Graphene has high chemical stability and versatile platform for photocatalysis due to specific surface area $(2630 \mathrm{~m} 2 / \mathrm{g})$, excellent electrical conductivity and outstanding optical transmittance. At present major problems affecting the mankind are energy crisis and environmental problems. The potential solution of these problems is utilization of solar energy for photocatalytic degradation using suitable semiconducting photocatalysts. In the process of photocatalysis, graphene to enhancing the separation and exchange of photo-generated charge carriers from semiconductors [4,5]. Many researchers have synthesized a number of graphene-supported semiconductors such as activated carbonsilica $\left(\mathrm{SiO}_{2} / \mathrm{AC}\right), \mathrm{GO}-\mathrm{CuO}, \mathrm{GO}-\mathrm{TiO}_{2}$ and $\mathrm{NiO} /$ graphene oxide for the removal of water pollutants as organic and inorganic to enhance its catalytic activity [5-9]. Therefore, researchers have tried to improve distinguishable nanocomposites/ nanoparticles for reduction of heavy metal ions to overcome this tricky. Hybridization of graphitic materials with $\mathrm{CuO}$ offers the efficient photocatalytic activity [10, 11]. For this purpose, $\mathrm{CuO}$ has been reported to be one of the best metal oxides that can be grown on graphene sheets. $\mathrm{CuO}$ has unique physical and chemical properties such as large specific surface area [12], excellent solar light absorbance [13], and a narrow band gap (Eg 1.2 eV) [14], rendering this material useful for many practical applications. $\mathrm{CuO}$ has also been explored in various fields such as optoelectronics [15], electronics [16],

gas sensing [17], solar cells [18], batteries [19] as well as heterogeneous catalysis [20].

In this study, we prepared and fabrication and exploration of the potential of a hybrid materials specifically graphene- $\mathrm{CuO}$ nanocomposites by wet chemical method for degradation of $\mathrm{Pd}(\mathrm{II})$ ion under solar light. The decomposition kinetics and mechanism of the photocatalysts were also studied.

\section{Experimental Methods}

\subsection{Chemicals}

The materials graphite flakes $(+200$ mesh) were commercially obtained from Sigma-Aldrich, copper acetate dihydrate $\left[\left(\mathrm{CH}_{3} \mathrm{COO}\right)_{2} \mathrm{Cu} .2 \mathrm{H}_{2} \mathrm{O}\right]$, sodium hydroxide $[\mathrm{NaOH}]$, sodium nitrate $\left[\mathrm{NaNO}_{3}\right]$, hydrogen peroxide $\left[\mathrm{H}_{2} \mathrm{O}_{2}\right]$, sulfuric acid $\left[\mathrm{H}_{2} \mathrm{SO}_{4}\right]$, hydrochloric acid [ $\left.\mathrm{HCl}\right]$, and potassium permanganate $\left[\mathrm{KMnO}_{4}\right]$ all these chemicals procured from the Merck and used without further refinement, Ethyl alcohol $\left[\mathrm{C}_{2} \mathrm{H}_{5} \mathrm{OH}\right], A R, 99.9 \%$ (Jiangsu Huaxi International Trade Co.Ltd., Made in china). Throughout the experiment double distilled water was used.

\subsection{Synthesis of Graphite Oxide}

Graphite oxide was prepared by the modified Hummers method [21]. In a typical procedure, about $5 \mathrm{~g}$ of graphite flakes was added to $115 \mathrm{~mL}$ of concentrated (98\%) $\mathrm{H}_{2} \mathrm{SO}_{4}$ in an ice bath with stirring for $30 \mathrm{~min}$. A $15 \mathrm{~g}$ of $\mathrm{KMnO}_{4}$ was added slowly to the above mixture with stirring and cooling for $30 \mathrm{~min}$. Subsequently, $2.5 \mathrm{~g}$ of $\mathrm{NaNO}_{3}$ was added with continuous stirring for $1 \mathrm{~h}$. So that the temperature of the mixture maintained below $15^{\circ} \mathrm{C}$ during that time. The temperature of mixture then raised upto $40{ }^{\circ} \mathrm{C}$ with water bath, and the mixture was continuously stirred for $30 \mathrm{~min}$. After that, the mixture was diluted by $800-1000 \mathrm{~mL}$ of distilled water, the temperature of which then raised to $98^{\circ} \mathrm{C}$. The mixture was then added by $\mathrm{H}_{2} \mathrm{O}_{2}(30 \%)$ until gas evolution ceased followed by filtering. The color of the dispersion turned from black to yellow. The product was washed repeatedly with $1 \mathrm{M} \mathrm{HCl} \mathrm{(5 \% )} \mathrm{and} \mathrm{distilled} \mathrm{water} \mathrm{until} \mathrm{the} \mathrm{pH}$ value of the product arrived at near 7 . Then the product was dried in an air oven at 60 ${ }^{\circ} \mathrm{C}$ to obtain graphite oxide.

\subsection{Synthesis of GO-CuO Nanocomposite}

To prepare a colloidal suspension of GO [22], about $60 \mathrm{mg}$ of asprepared graphite oxide was dispersed in $60 \mathrm{~mL}$ of ethanol by sonication for $1 \mathrm{~h}$. Consequently copper acetate $0.25 \mathrm{M}$ was added in to the dispersion and then add drop wise $1 \mathrm{M}$ of $\mathrm{NaOH}$ solution up to $\mathrm{pH}=10$, which was 
calculated by $\mathrm{pH}$ meter. The total mixture was maintained at $140{ }^{\circ} \mathrm{C}$ for 12 hours under $\mathrm{N}_{2}$ atmosphere. The product was washed several times with first by ethanol and thereafter distilled water. After that GO-CuO dried at $80^{\circ} \mathrm{C}$ overnight in hot air oven. The synthesis procedure was shown in below (Fig. 1).

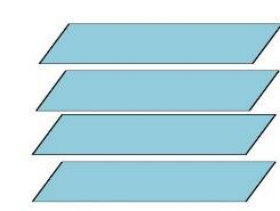

Graphite Flakes

\section{$\underset{\text { Oxidation }}{\stackrel{\text { Hummer's Method }}{\longrightarrow}}$}

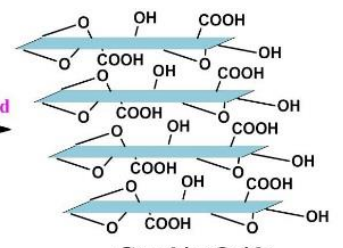

Graphite Oxide (More layers)

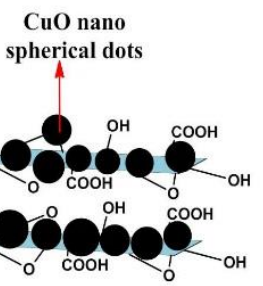

GO-CuO nanocomposite

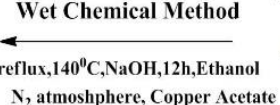

$\mathrm{N}_{2}$ atmoshphere, Copper Acetate

$1 \mathrm{~h}$ Sonication
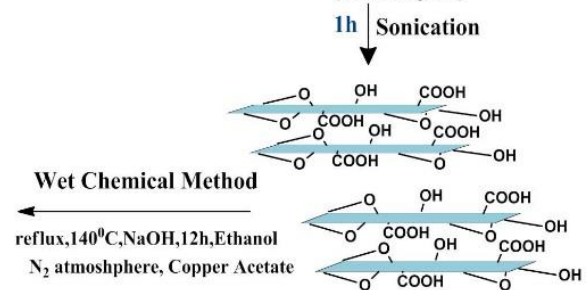

Graphene Oxide (Few layers)

Fig. 1 Chemical route synthesis of GO-CuO nanocomposites

\subsection{Instrumentation}

The structure and morphology of the samples were characterized by X-

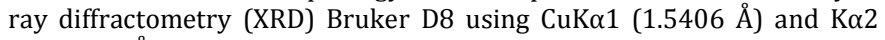
$(1.54439 \AA)$ radiations, Morphologies of as-obtained products were studied by scanning electron microscope (SEM) imaging with energy dispersive Absorption X-ray spectroscopy (EDAX) or Energy dispersive spectrum (EDS) using a Carl Zeiss model Ultra 55 microscope operating at 5 and $20 \mathrm{kV}$, Structure analysis were conducted by a transmission electron microscope (TEM) measurements were performed on a Tecnai G2FEI F12 I at $200 \mathrm{kV}$, Carbon coated TEM grids were used before taking the images of the compounds. Raman spectra were recorded using a WiTec alpha 200 SNOM system. The $\mathrm{pH}$ of the solution was checked by using Elico $\mathrm{pH}$ meter.

\subsection{Photocatalytic Activity Studies}

To evaluate the application activity of the GO-CuO nanocomposites, degradation experiments on the palladium solution were done under the presence of solar light condition. In our frame work GO-CuO nanocomposites were show very good photocatalytic activity test. In this case $10 \mathrm{ppm}$ of palladium solution in $50 \mathrm{~mL}$ distilled water and $50 \mathrm{mg}$ of catalyst were taken in round battle flask. First, CR solution with catalyst were maintained under magnetic stirring in darkness for one hour because to reach CR solution adsorption-desorption equilibrium position. Then this solution kept under the sun light continuously stirred on magnetic stirrer after each 10 min equal interval of time $2 \mathrm{~mL}$ of solution was collected in the test tube. The concentration of the clean transparent zinc solution was analyzed by checking the absorbance at 400 to $600 \mathrm{~nm}$ with the UV-vis spectrophotometer, which denoted as $\mathrm{C}_{\mathrm{t}}$. In this case dried GO-CuO nanocomposites shown the good photocatalytic activity compared with the 300 and $600{ }^{\circ} \mathrm{C}$ calcination compound in the presence of sun light.

\section{Results and Discussion}

The crystalline nature and orientation of the as-synthesized Graphite oxide, $\mathrm{CuO}$ and GO-CuO nanocomposite was analyzed by powder X-ray diffraction (PXRD) as shown in (Fig. 2). For graphite oxide an intense crystalline peak around $9.92^{\circ}$. All the samples exhibit analogous diffraction peaks in terms of $\mathrm{CuO}$ framework. The dominant peaks located at ca. $35.55,46.26,48.70,53.54,58.33,61.55,66.22$ and $66.14^{\circ}$ are indexed to (111), (111), (202), (020), (202), (113), (311) and (202) crystallographic planes of monoclinic CuO (JCPDS File Card No. 89-5899) consistent with GO-CuO composite. Where the diffraction peaks can be readily indexed to $\mathrm{CuO}$ with (111) and (111) planes confirm the presence of $\mathrm{CuO}$ in the composite catalyst [23]. The XRD pattern demonstrate the presence of a monoclinic phase of $\mathrm{CuO}$ with no indication of $\mathrm{Cu}_{2} \mathrm{O}$ and $\mathrm{Cu}(\mathrm{OH})_{2}$ phase. No characteristic diffraction peaks for GO are observed in the pattern because of the low amount and the relatively low diffraction intensity of GO.

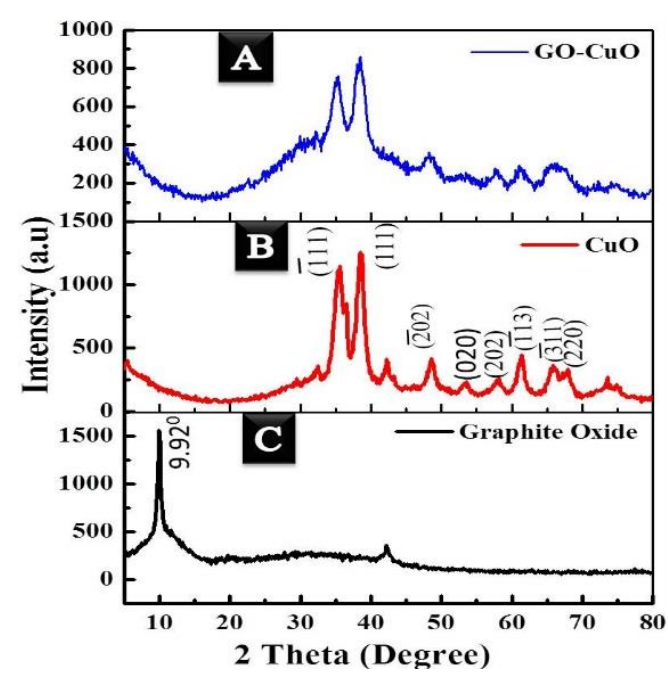

Fig. 2 P-XRD pattern of the (A) GO-CuO and (B) CuO and (C) Graphite oxide

The Raman spectra of GO and GO-CuO composites are shown in (Fig. 3). The $D$ and $G$ bands were observed in the range of $1000-2000 \mathrm{~cm}^{-1}$. Generally in GO based samples, the disorder-induced D bands arise from the tangential stretch and sp3-hybridized carbon and the $G$ band represents the crystalline graphite with $\mathrm{E}_{2 \mathrm{~g}}$ zone center mode; moreover, the $I_{D} / I_{G}$ ratio depends strongly on the amount of disorder in the graphitic material [24]. The $I_{D} / I_{G}$ ratio should increase when more defects are introduced into GO. According to Fig. 3, the $\mathrm{I}_{\mathrm{D}} / \mathrm{I}_{\mathrm{G}}$ ratio of $\mathrm{GO}-\mathrm{CuO}$ composite is 0.998 which is higher than the 0.990 calculated from GO. That is to say, $\mathrm{CuO}$ modification can be effective in bringing an amount of defects into the structure of GO.

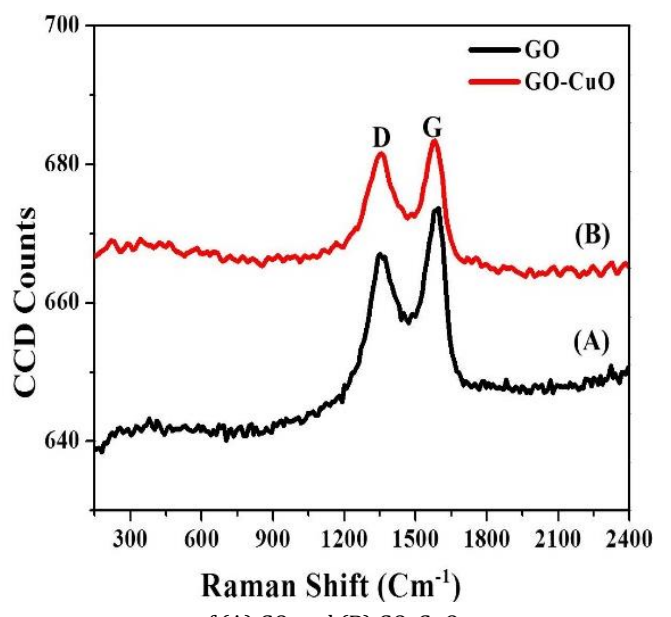

Fig. 3 Raman measurements of (A) GO and (B) GO-CuO

The SEM of nanocomposite was taken as powder synthesized, images were taken on carbon tape. Fig. 4A shows the SEM images it is unambiguous that the morphology of intercalated nanocomposite particles are really in nanosize and it shows the clumsy morphology due to the aggregation of particles in the solution while synthesis. Fig. 4B shows the Energy dispersive spectrum (EDS) results of the GO-CuO nanocomposite. $\mathrm{Cu}, \mathrm{O}, \mathrm{C}$ and $\mathrm{Cu}$ elements are observed.
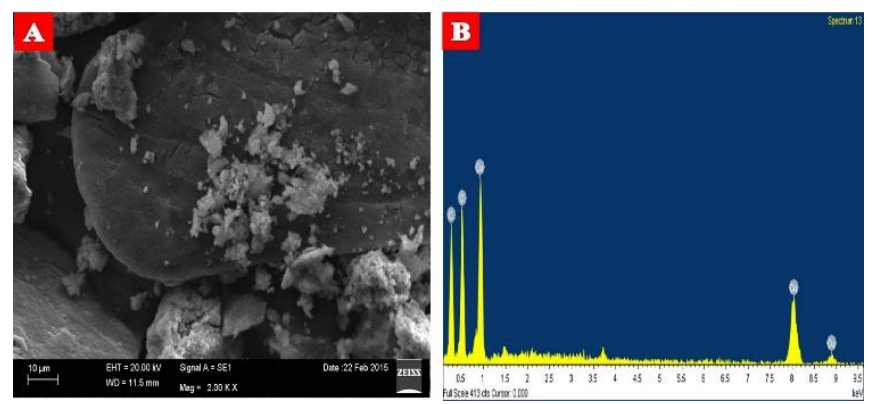

Fig. 4 (A) SEM image and (B) EDS of GO-CuO composite

Fig. 5 illustrates the typical TEM images of GO-CuO nanocomposite. It can be clearly seen that the exfoliated GO sheet was decorated by spherical dot $\mathrm{CuO}$, with size $<10 \mathrm{~nm}$. Fig. 5(D) displays selective area electron 
diffraction (SAED) pattern of hybrid material shows the fusion of super lattices which are characteristic nature of the layer structure of any kind of materials.
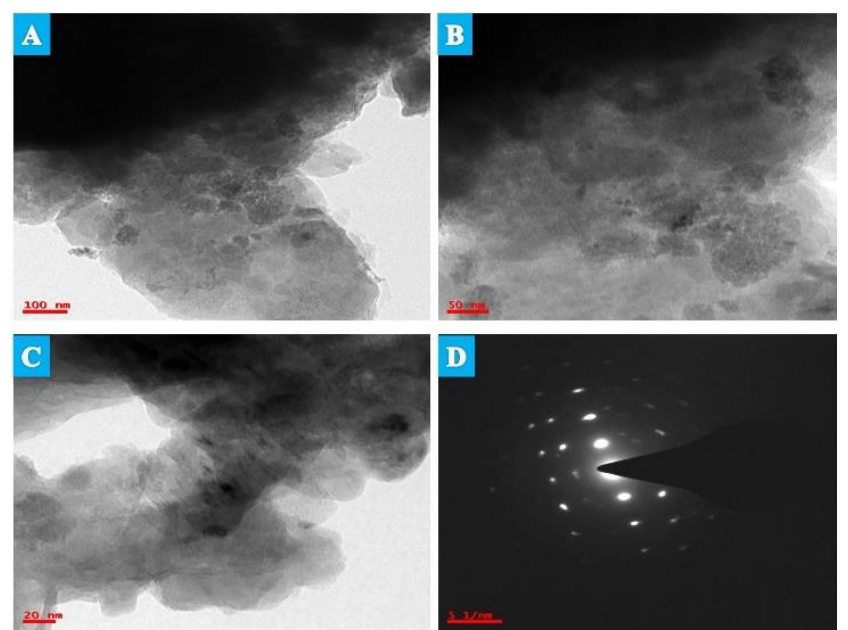

Fig. 5 (A, B, C) TEM micrographs at different magnification and (D) SAED pattern of GO-CuO composite

To illustrate the synergetic enhance of photocatalytic performance of GO-CuO Nanocomposites toward a heavy metal Pd(II) ions, the daylight driven photocatalytic reduction of $\mathrm{Pd}(\mathrm{II})$ in water was carried out at regular time intervals. The adsorption of these solutions decreased gradually with irradiation time. The characteristic adsorption of palladium almost disappeared after 70 min (Fig. 6(A)). The dried compound was $81.9 \%$ degraded in $70 \mathrm{~min}$ time (Fig. $6(\mathrm{~B})$ ), $300^{\circ} \mathrm{C}$ calcinations compound was degraded $72.6 \%$ in 70 min (Fig. $6(\mathrm{C})$ ) and finally $600{ }^{\circ} \mathrm{C}$ calcinations compound was degraded 63.5\% 70 min time taken (Fig. 6(D)). Because increase the calcinations temperature the particle size also increase that means the particle agglomeration was formed. This reason $600{ }^{\circ} \mathrm{C}$ compound was less degradation $\%$ compared with the dried and $300{ }^{\circ} \mathrm{C}$ calcination compounds.
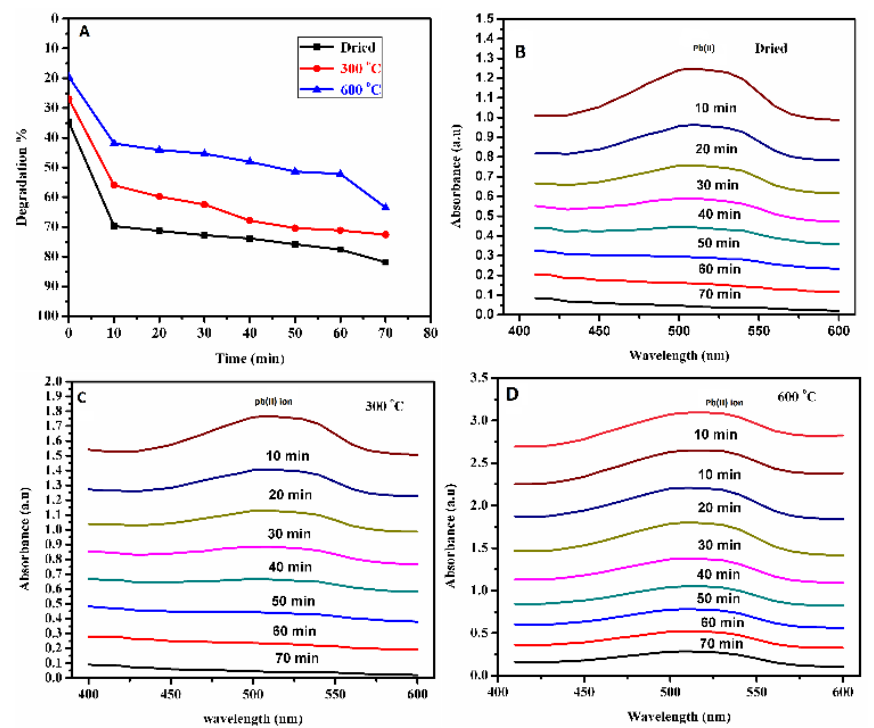

Fig. 6 Photocatalytic degradation of Pd(II) with GO-CuO nanocomposite as catalyst and comparison of different temperature

\section{Conclusion}

A simple and effective method was established to prepare GO-CuO photocatalyst by using graphene and $\mathrm{CuO}$. Excellent circulated $\mathrm{CuO}$ nanocubes with an average size ranged between 5-10 $\mathrm{nm}$ were deposited on graphene via the wet chemical method under $\mathrm{N}_{2}$ atmosphere. GO-CuO nanocomposite effectively reduces mutagenic aqueous solution of $\mathrm{Pd}(\mathrm{II})$ under natural daylight driven. The $300{ }^{\circ} \mathrm{C}$ calcination of GO-CuO photocatalyst have been showed high photocatalyst activity with $600{ }^{\circ} \mathrm{C}$ calcination of $\mathrm{GO}-\mathrm{CuO}$ photocatalyst. Graphene based composite materials indication good-looking environmental applications such as toxic pollutants removal in terms of their cheap cost, simple handling and high degradation performance. Hence, photocatalytic reduction using GO-CuO nanocomposite is a most suitable, suitable and low cost effective technique for further treatment of industrial wastewater.

\section{Acknowledgements}

We gratefully acknowledge instrumental support University of Hyderabad, IIT Madras, IICT.

\section{References}

[1] H. Ebrahimzadeh, N. Tavassoli, M.M. Amini, Y. Fazaeli, H. Abedi, Determination of very low levels of gold and palladium in wastewater and soil samples by atomic absorption after preconcentration on modified MCM-48 and MCM-41 silica, Talanta 81 (2010) 1183-1188.

[2] B. Salih, O.C. Elikbıak, S. Doker, M. Dogan, Matrix elimination method for the determination of precious metals in ores using electrothermal atomic absorption spectrometry, Anal. Chim. Acta 587 (2007) 272-280.

[3] S.I. Ishikawa, K. Suyama, K. Arihara, M. Itoh, Uptake and recovery of gold ions from electroplating wastes using eggshell membrane, Bioresour. Technol. 81 (2002) 201-206.

[4] Q.J. Xiang, J. G. Yu, M. Jaroniec, Graphene-based semiconductor photocatalysts, Chem. Soc. Rev. 41 (2012) 782-796.

[5] N. Zhang, M.Q. Yang, S. Liu, Y. Sun, Y.J. Xu, Waltzing with the versatile platform of graphene to synthesize composite photocatalysts, Chem. Rev. 115 (2015) 10307-10377.

[6] M. Karnib, A. Kabbani, H. Holail, Z. Olama, Heavy metals removal using activated carbon, silica and silica activated carbon composite, Energy Procedia 50 (2014)113-120.

[7] S. Archana, K. Yogesh Kumar, S. Olivera, B.K. Jayanna, H.B. Muralidhara, A Ananda, C.C. Vidyasagar, Development of multipurpose CuO-GO nanocomposites for heavy metals adsorption and super capacitor applications, Energy Environ. Focus 5 (2016) 1-11.

[8] Y. Cong, M. Long, Z. Cui, X. Li, Z. Dong, G. Yuan, J. Zhang, Anchoring a uniform $\mathrm{TiO}_{2}$ layer on graphene oxide sheets as an efficient visible light photocatalyst, Appl. Surf. Sci. 282 (2013) 400-407.

[9] X. Rong, F. Qiu, C. Zhang, L. Fu, Y. Wang, D. Yang, Adsorption-photodegradation synergetic removal of methylene blue from aqueous solution by $\mathrm{NiO} / g r a p h e n e$ oxide nanocomposite, Powder Technol. 275 (2015) 322-328.

[10] N. Yusoff, N. Huang, M. Muhamad, S. Kumar, H. Lim, I. Harrison, Hydrotherma synthesis of $\mathrm{CuO} /$ functionalized graphene nanocomposites for dye degradation, Mater. Lett. 93(2013) 393-396.

[11] L. Cheng, Y. Wang, D. Huang, T. Nguyen, Y. Jiang, H. Yu, et al., Facile synthesis of size-tunable CuO/graphene composites and their high photocatalytic performance, Mater. Res. Bull. 61 (2015) 409-414.

[12] C. Batchelor-McAuley, Y. Du, G.G. Wildgoose, R.G. Compton, The use of copper(II) oxide nanorod bundles for the non-enzymatic voltammetric sensing of carbohydrates and hydrogen peroxide, Sens. Actuator B: Chem. 135(1) (2008) 230-235.

[13] X. Xiao, L. Miao, G. Xu, L. Lu, Z. Su, N. Wang, S. Tanemura, A facile process to prepare copper oxide thin films as solar selective absorbers, Appl. Surf. Sci. 257(24) (2011) 10729-10736.

[14] M. Vila, C. Díaz-Guerra, J. Piqueras, Optical and magnetic properties of CuO nanowires grown by thermal oxidation, Jour. Phys. D: Appl. Phys. 43(13) (2010) 135403-135408.

[15] S. Manna, K. Das, S. De, Template-free synthesis of mesoporous CuO dandelion structures for optoelectronic applications, ACS Appl. Mater. Interf. 2(5) (2010) 1536-1542.

[16] L. Liao, Z. Zhang, B. Yan, Z. Zheng, Q. Bao, T. Wu, et al., Multifunctional CuO nanowire devices: p-type field effect transistors and CO gas sensors, Nanotechnol. 20(8) (2009) 085203-085208.

[17] X. Jia, H. Fan, W. Yang, Hydrothermal synthesis and primary gas sensing properties of CuO nanosheets, J. Dispersion Sci. Technol. 31(7) (2010) 866869.

[18] D.S. Darvish, H.A. Atwater, Modeling, synthesis, and characterization of thin film copper oxide for solar cells, Paper presented at the photovoltaic specialist conference (PVSC), 34th IEEE, California Institute of Technology, Pasadena, USA, 2009.

[19] J. Xiang, J. Tu, L. Zhang, Y. Zhou, X. Wang, S. Shi, Simple synthesis of surfacemodified hierarchical copper oxide spheres with needle-like morphology as anode for lithium ion batteries, Electrochim. Acta 55(5) (2010) 1820-1824.

[20] F. Teng, W. Yao, Y. Zheng, Y. Ma, Y. Teng, T. Xu, et al., Synthesis of flower-like $\mathrm{CuO}$ nanostructures as a sensitive sensor for catalysis, Sens. Actuator B: Chem 134(2) (2008) 761-768.

[21] J. Zhu, G. Zeng, F. Nie, X. Xu, S. Chen, Q.F. Han, X. Wang, Decorating graphene oxide with $\mathrm{CuO}$ nanoparticles in a water-isopropanol system, Nanoscale 2 (2010) 988-994.

[22] P. Pandey, M.S. Packiyaraj, H. Nigam, G.S. Agarwal, B. Singh, M.K. Patra, Antimicrobial properties of $\mathrm{CuO}$ nanorods and multi-armed nanoparticles against $B$. anthracis vegetative cells and endospores, Beilstein J. Nanotechnol. 5 (2014) 789-800.

[23] M. Suleiman, M. Mousa, A. Hussein, B. Hammouti, T.B. Hadda, I. Warad Copper(II)-oxide nanostructures: Synthesis, characterizations and their applications-review, J. Mater. Environ. Sci. 4(5) (2013) 792-797.

[24] J. Song, L. Xu, C. Zhou, R. Xing, Q. Dai, D. Liu, H. Song, Synthesis of graphene oxide based $\mathrm{CuO}$ nanoparticles composite electrode for highly enhanced nonenzymatic glucose detection, ACS Appl. Mater. Interf. 5 (2013) 1292812934. 